\title{
Imagen pública y política de la emperatriz Teodora. Un estudio a partir de la obra de Procopio de Cesarea
}

\author{
Isabel LASALA NAVARRO \\ Universidad Internacional de la Rioja \\ isabel.lasala@unir.net
}

Recibido: 26 de abril de 2013

Aceptado: 25 de junio de 2013

\section{RESUMEN}

El presente artículo tiene como objeto mostrar el importante papel que la emperatriz Teodora desempeñó en el gobierno de su esposo, el emperador Justiniano, demostrando la importancia de lo femenino en la construcción de la imagen de la casa imperial en este momento histórico. Se parte para ello del análisis de la obra de Procopio de Cesarea y, muy especialmente, de su Historia Secreta, especialmente dura, en su redacción, con la emperatriz. De la misma se destaca su posición en cuatro ámbitos fundamentales: correspondencia, justicia, ceremonial y recursos financieros. El estudio se completa con el análisis de otras dos obras del mismo autor, De Bellis y De Aedeficiis, así como con el papiro del Cairo y las impresiones de Juan el Lidio y Zonaras, que vienen a demostrar la relevancia política de la emperatriz en el marco del gobierno de su esposo.

Palabras clave: Teodora. Procopio de Cesarea. Justiniano. Imagen pública y política.

\section{Empress Theodora's public and political image: An analysis based on Procopius of Caesarea's work}

\begin{abstract}
The aim of this article is to present the significant role played by Empress Theodora in his husband's government, proving the relevance of the female element in the build-up of the image of the imperial house in that historical moment. The paper is based on an analysis of Procopius of Caesarea's Secret History, which is particularly hard on the Empress. In this work we can emphasize her position in four important areas: correspondence, justice, ceremonial and financial resources. The article is completed with the analysis of two other Procopius's works, De Bellis and De aedeficiis, just like the Aphrodite Papyri and the impressions of John the Lydian and Zonaras, which prove the political relevance of the Empress in his husband government frame.
\end{abstract}

Key words: Theodora. Procopius of Caesarea. Justinian. Public and political image. 
Hija de una actriz y un guarda de las bestias del circo en Constantinopla. ${ }^{1}$ Joven de vida libidinosa ${ }^{2}$ y esposa del mismísimo emperador Justiniano. Tras ser prácticamente obviada en De Bellis ${ }^{3}$ y alabada por su piedad en De aedificiis, ${ }^{4}$ la emperatriz Teodora aparece recibiendo duros ataques en la que, sin duda, se ha convertido en la obra más célebre de Procopio de Cesarea, su Historia Secreta. Según expone el propio autor, tras la muerte de los protagonistas de su obra y despojado del peso de un posible castigo por parte de los mismos, por fin se siente libre para criticarlos abiertamente y sin reservas. Así será. Él, débil, ella, manipuladora. La antítesis del emperador ideal y la antítesis de su perfecta compañera. Procopio aprovecha la obra para mostrar al mundo en general, y a las generaciones venideras en particular, todas las malas acciones del matrimonio compuesto por Justiniano y Teodora, a los que, junto a Belisario ${ }^{5}$ y su esposa Antonina, ${ }^{6}$ no duda en calificar de "tiranos". ${ }^{7}$ Sin embargo, y como se expondrá a lo largo del presente artículo, las críticas son mucho más duras hacia Teodora que hacia el propio emperador. Así, ella aparece representada como la instigadora de las malas acciones de Justiniano, quien, por otra parte, de carácter débil y fácilmente manipulable por una mujer de las características de su esposa, casi aparece disculpado - a pesar de la descripción que Procopio lleva a cabo en el libro VI de su Historia Secreta ${ }^{8}$ por la fragilidad de su voluntad.

Sin duda, las duras críticas hacia la emperatriz no fueron gratuitas. Una o varias razones de fondo empujaron a Procopio a redactar una obra crítica y de reprobación de aquellos a los que anteriormente, y en otras obras, había alabado con mayor o menor vehemencia. ${ }^{9}$ A este respecto, cabe destacar que Procopio escribió su obra con una doble finalidad; una declarada en su proemio, y que aparece redactada por él mismo en primera persona en las líneas iniciales de su Historia Secreta y, junto a ésta, otra no declarada por el autor, pero que se desprende del contenido de su obra, y que es, sin duda, de mucho mayor calado que la anterior. En cuanto a la finalidad declarada por Procopio, ésta no es otra que advertir a los futuros tiranos del fin que les espera de seguir por el camino del despotismo y la opresión con respecto al gobierno del Estado en lugar de avanzar por el de la virtud y la probidad. Y es que, como expone el autor bizantino, el fin de los protagonistas de su obra debe servir de ejemplo de lo que ocurre cuando se cometen viles acciones. Asimismo, advierte, los actos de los tiranos siempre acabarán quedando en la memoria de la posteridad y serán así siempre re-

1 PLRE IIIB, Teodora I, 1240-1241.

2 Proc. Cesarea, Hist. Secr., 9.15-16.

3 Es mencionada en ocho ocasiones: $1.24 .32-41 ; 1.25 .4-5 ; 1.25 .22 ; 1.25 .30 ; 2.30 .49 ; 4.9 .13 ; 7.30 .3$; 7.31.13., de las cuales las siete últimas de pasada.

4 Junto con Justiniano, 1.9.5-10, 1.11.23.

5 PLRE IIIA, Fl. Belisarius I, 181-224.

6 PLRE IIIA, Antonina 1, 91-93.

7 Proc. Cesarea, Hist. Secr., 1.8-10.

8 6. 22-33; al hilo de las críticas a Justiniano resulta interesante leer a P. Heather, quien en el contexto de las razones para explicar la caída del Imperio romano de Oriente señala cómo, en la línea de crítica al emperador iniciada por Procopio, la línea tradicional carga las tintas sobre las expediciones de aquel, "cargadas de insolencia y de excesiva expansión imperialista", asociación "difícilmente sostenible" para este autor. Vid. HEATHER 2010, 436.

9 Valga como ejemplo su alusión a la piedad del matrimonio en: Proc. Cesarea, Aedif., 1.9.5. 
cordados por las generaciones venideras. Finalmente, Procopio lanza un non tibi soli para todos aquellos que sufrirán las acciones de tiranos en el futuro, esperando que el sufrimiento colectivo aplaque el individual de cada uno de ellos. Es esta finalidad, preventiva, de nuevas malas acciones en el gobierno por parte de futuros tiranos, la que Procopio expone en el proemio de su obra; sin embargo, y a tenor del texto de la misma, no parece ser la única. La lectura del texto sugiere que la finalidad preventiva e incluso didáctica parece superada por el deseo de desprestigiar al emperador reinante en el momento de la redacción de sus páginas. Teniendo en cuenta esta finalidad no declarada pero latente, la crítica de Teodora no puede medirse con los mismos parámetros con los que se mide la realizada a Justiniano, al fin y al cabo el emperador reinante y cabeza visible del Imperio para sus súbditos y la posteridad. Y es que de querer desprestigiar su legado, la crítica al mismo estaría perfectamente justificada, pues se trataba del emperador, el vértice político del Imperio; sin embargo, la crítica a su esposa, mucho más virulenta a tenor del texto, podría parecer desproporcionada, puesto que al fin y al cabo no es ella la que brinda su nombre a las listas de emperadores que ha legado la historia. Ahora bien, ¿realmente debe sorprender la crítica a la emperatriz? y, ¿tiene aquella alguna justificación?

Como propone acertadamente Brubaker, el autor bizantino utiliza el ataque a Teodora como vía para desacreditar a su marido, el emperador Justiniano. ${ }^{10}$ De este modo, la exposición pública de las acciones reprobables de Teodora -incluyendo el relato de los supuestos escándalos sexuales protagonizados en su juventud- ${ }^{11}$ no tendría tanto el objetivo de mostrar a las generaciones futuras lo que no debería hacerse, como el de desprestigiar al emperador gobernante. En este caso, la utilización de Teodora para injuriar a su marido implicaría que ésta habría ocupado una cierta posición de relevancia en la corte y en el Imperio. Y es que de haber sido una mera emperatriz consorte sin un papel activo en la política del Imperio, sin duda Procopio no la habría utilizado para denigrar a Justiniano y a la casa imperial. De lo anterior se desprende, y ésta va a ser la idea fundamental de las presentes líneas, la importancia de lo femenino en la creación de la imagen de la casa imperial durante el reinado de Justiniano. Una imagen que podía ser difamada tanto por la acción del elemento masculino, el emperador, como por el elemento femenino, su esposa, en caso de tener ésta importancia en la vida pública. Por supuesto, la emperatriz ocuparía una posición más o menos relevante según el carácter personal de aquella que co-ostentase la púrpura en cada momento pero, en el caso de Teodora, la utilización de sus actuaciones como definitorias de la vileza del emperador y de lo que éste representaba, implica que habría ostentado una importante imagen pública.

Procopio utiliza a Teodora en su Historia Secreta para denigrar al emperador y, quizás sin desearlo, pero gracias a ello, facilita una gran cantidad de información que, junto a la que se conoce por otros medios, como se expondrá, permite asegurar que la esposa de Justiniano realmente ostentó, como ocurriría con la emperatriz Irene

10 Brubaker 2005, 442.

11 Proc. Cesarea, Hist. Secr. 9.14-25. 
tres siglos más tarde, ${ }^{12}$ un papel público y político relevante no solo en la corte sino también en el Imperio.

En primer lugar, llama la atención que Procopio dice escribir su obra tras la muerte de sus actores ${ }^{13}$ Justiniano y Teodora, ante el miedo que le producían sus posibles represalias -en forma de muerte miserable $-{ }^{14}$ de haber escrito la verdad acerca de los mismos estando éstos en vida. Sin embargo, Teodora murió el 28 de junio de 548 d.C. ${ }^{15}$ y Justiniano el 14 de noviembre de 565 d.C., ${ }^{16}$ y la obra no fue escrita tras esta última fecha, sino que parece haber sido escrita hacia el año 550 d.C. ${ }^{17}$ Esta datación, en opinión de Signes Codoñer, implicaría que Procopio habría escrito su obra pensando en un próximo fallecimiento del emperador que finalmente no habría tenido lugar; ${ }^{18}$ sin embargo, y a tenor del poder de facto de la emperatriz para hundir las carreras de sus adversarios político-religiosos - poder que como se expondrá se desprende del contenido del texto- la datación de la obra parece sugerir que en realidad Procopio estaría esperando a que falleciera Teodora y que, por lo tanto, era ella la que le generaba el miedo de sufrir una muerte miserable.

Este temor, no tanto hacia el matrimonio imperial como hacia el elemento femenino del mismo, se descubre, pese a la declaración del proemio, en XVI.3, donde Procopio reconoce no haber narrado antes la verdad de la muerte de la reina Amalasunta, ${ }^{19}$ hija de Teodorico, por el temor que le provocaba la emperatriz, que habría sido parte activa en tal muerte según el mismo autor, ${ }^{20}$ habiendo sido el motivo para tal acción los recelos de aquella ante la posibilidad de perder el control sobre su marido. ${ }^{21}$ No escribe antes su obra, por tanto, no por la prevención que los dos integrantes de la pareja reinante le habrían producido, sino ante el miedo que la esposa del emperador le generaba. Temía, Procopio, morir de forma miserable. ¿Tanta era la influencia y el poder de Teodora que podía acabar con su vida por una mala crítica? ¿tanta su irascibilidad? A tenor del texto de Procopio: sí.

Las mujeres, en Bizancio, eran excluidas de la vida pública. Así, no podían ejercer ninguna función relacionada con el gobierno, como tampoco tareas relacionadas con la justicia o las propias de la banca. Como señala acertadamente Beaucamp, la

12 Ostrogorsky 1980, 177-182.

13 Proc. Cesarea, Hist. Secr. 1.2.

14 Vid. nota 8.

15 para la muerte de Teodora, Browning 1987, 128-130; MaAs 2005, 8; Moorhead 1994, 132; fuentes en PLRE IIIB, Theodora I, 1241.

16 Para la muerte de Justiniano, Browning 1987, 163-166; MAAs 2005, 8; Moorhead 1994, 176-177; fuentes en PLRE II, Iustinianus 7, 645-648.

17 El debate acerca de la fecha de composición de la Historia Secreta aparece muy bien sintetizado en Signes CodoñEr 2000, 48-53. La fecha más aceptada es la mencionada del 550 d.C., aunque algún autor la lleva incluso hasta el 558-59 d.C. No obstante, nunca antes del 550 d.C.

18 Signes Codoñer 2000, 144, nota 4. Gracias a la obra de Procopio de Cesarea -Hist. Secr. IV, 1-sabemos que el emperador Justiniano, hacia el año 542 d.C., estuvo próximo a fallecer víctima de la peste. Sin embargo, parece razonable pensar que para el año 550 d.C. ya estaría recuperado de dicha enfermedad y, por lo tanto, no debió de ser ésta la causa de que Procopio pudiera creer en su pronto fallecimiento, con lo que no nos sirve, pues, como excusa para escribir su Historia Secreta.

19 PLRE II, Amalasuintha, 65.

20 Proc. Cesarea, Hist. Secr. 16.1-7.

21 Vid nota 19. FISCHER 1978, 271-272. 
excepción más evidente a esta exclusión, la del ejercicio del poder imperial por una mujer, no aparece contemplada por el derecho, así, "la emperatriz que aparece en los textos jurídicos es la mujer del emperador, y no la emperatriz reinante". ${ }^{22}$ Ahora bien, incluso si su poder no era aceptado específicamente en los textos jurídicos, la realidad era que las emperatrices, en muchas ocasiones, lo ejercían de facto. Y es que la emperatriz, si ostentaba una posición oficial en la estructura política del Imperio, tan solo dependía de su propia capacidad para desarrollarla, en función de sus propias facultades, así como de la incapacidad o el carácter más o menos influenciable de su esposo. Este es el caso de Teodora, de cuyo poder en la corte de Justiniano está plagada de ejemplos la Historia Secreta de Procopio de Cesarea, como pasa a exponerse a continuación..$^{23}$

Uno de los ejemplos más claros de la situación privilegiada que, desde el punto de vista del gobierno, habría ostentado Teodora en la corte, viene indicado por el hecho de que Procopio hace constantemente referencia a ella y a su marido como si ambos se tratasen de un único individuo a la hora de tomar decisiones de índole política. Son abundantes las ocasiones en las que el autor de la Historia Secreta se refiere no únicamente al emperador, sino a ambos, en plural, para aludir a las decisiones -crueles y despiadadas en opinión de Procopio- que tomaron juntos. Como señala este autor, en su vida en común, nunca actuaron el uno sin el otro ${ }^{24} \mathrm{y}$ así queda de manifiesto a lo largo de todo el libro XI, en el que viene a exponer el gobierno conjunto de ambos. De este modo, y como muestra Procopio, la emperatriz tuvo la potestad suficiente como para autorizar a una facción del circo, la de los azules, a actuar libremente y sin control contra la facción rival, así como para dictar órdenes al respecto de la misma. ${ }^{25}$ Juntos persiguieron a los más prósperos del Imperio, incluidos los senadores, y les arrebataron sus fortunas. ${ }^{26}$ Juntos, como demonios con forma humana y afán destructor, ${ }^{27}$ llevaron al imperio a la desgracia, ${ }^{28} \mathrm{y}$ es que juntos maquinaban la destrucción de los hombres. ${ }^{29}$

Asimismo, señala Procopio, Teodora se consideraba autorizada para dirigir todos los asuntos de estado con su solo criterio ${ }^{30}$ y se creía con derechos para administrar todo el Imperio romano hasta el punto de que si el emperador encargaba a alguien una misión sin el conocimiento de ella, aquél acababa perdiendo su cargo y sufría una muerte infame. ${ }^{31}$ Se consideraba autorizada y actuaba en consecuencia. En este sentido, su posición de poder queda también de manifiesto ante los nombramientos

22 BeAucamp 1977, 149.

23 Pese a que A. Cameron hace derivar la influencia de la emperatriz Teodora de su proximidad personal al emperador y de la generosidad que de él recibía, la realidad es que no deben ser obviadas sus capacidades y destrezas públicas y políticas, que sin duda habrían jugado un lugar fundamental en su carrera en la corte de Justiniano (CAmeron 1985, 82, nota 99).

24 Proc. Cesarea, Hist. Secr. 11.13.

25 Proc. Cesarea, Hist. Secr. 11.16-17.

26 Proc. Cesarea, Hist. Secr. 11.40; 12.12.

27 Proc. Cesarea, Hist. Secr. 12.13-17.

28 Proc. Cesarea, Hist. Secr. 11.16-17.

29 Proc. Cesarea, Hist. Secr. 13.8. Signes Codoñer 2000, 235.

30 Proc. Cesarea, Hist. Secr. 17.27. Signes Codoñer 2000, 258.

31 Proc. Cesarea, Hist. Secr. 15.9. Signes Codoñer 2000, 244. 
que promulgó y que son relatados por Procopio en su obra. Así, Teodora nombró magistrados a dos sujetos despreciables y sin distinción alguna ${ }^{32}$ para reconfortar a dos mujeres a las que previamente había obligado a contraer matrimonio con ellos. Y éstas no debieron ser las únicas magistraturas nombradas por la emperatriz, puesto que más adelante Procopio volverá a señalar que, Teodora, cuando designaba personas para las magistraturas y cargos sacerdotales..., ${ }^{33}$ términos que parecen indicar que tales nombramientos debían ser frecuentes y estaban a la orden del día. ${ }^{34}$

Siguiendo con las acciones de gobierno, cabe exponer otras prácticas concretas que la emperatriz llevó a cabo conjuntamente con Justiniano, así como destacar las que éste ejecutó a instancias de la misma; prácticas estas últimas que vienen a ser indicativas del margen de maniobra que Teodora tenía en la corte y de su capacidad de influencia sobre su esposo. Como señala Procopio, Justiniano no dudaba en traicionar a sus amigos con tal de complacer a su mujer, lo que, de ser cierto, ofrece una idea de cuál habría sido su capacidad de maniobra en la corte. ¡Si Juan Crisóstomo hubiera levantado la cabeza! ${ }^{35}$ De este modo, y en este contexto de cooperación en el ejercicio del poder, ambos nombraron, juntos, a Pedro Barsimes ${ }^{36}$ sucesor de Juan de Capadocia, ${ }^{37}$ por el mero motivo de que agradaba especialmente a la emperatriz. ${ }^{38}$ También el emperador quitó el mando de sus tropas al general Belisario a instancias de Teodora ${ }^{39} \mathrm{y}$, juntos decidieron dejar sin castigo a Salomón ${ }^{40}$ quien había asesinado a Pegasio ${ }^{41}$ tras haber pagado éste su rescate para liberarlo de los leuatas. Asimismo, el hecho de que Procopio haga aparecer a Belisario preocupado, en el texto de la Historia Secreta, porque los miembros de la pareja imperial, en la que se incluye Teodora, no estaban bien dispuestos hacia él, ${ }^{42}$ en el contexto de su exclusión de la vida pública y social del Imperio, implicaría que la opinión política de Teodora también contaba, y lo hacía tanto como la de su esposo, pues se refiere a los mismos en plural.

Pero Teodora no solo actuó en el gobierno del Imperio junto con su marido o influyendo las decisiones de éste, sino que también en solitario acometió acciones de gran calado político. Y es que a tenor de la siguiente afirmación de Procopio: Nadie tenía libertad alguna para hablar o pedir nada, a menos que ella lo ordenase. El gobierno se convirtió así en un régimen de esclavos de los que ella era dueña y señora ${ }^{43}$ en la

\footnotetext{
32 Proc. Cesarea, Hist. Secr. 17.13. Signes Codoñer 2000, 256.

33 Vid. nota 30.

34 Como demuestran los casos de los eclesiásticos Antimo, al que promocionó al patriarcado de Constantinopla, y Teodosio, promocionado al de Alejandría. Vid. Signes CodoñER 2000, 258, nota 209.

35 CLARK 1993, 125-126; para la visión de las mujeres y la actitud que aquellas debían presentar ante sus esposos resulta muy interesante CLARK 1982, 1-15.

36 PLRE IIIB, Petrus 9, 999-1002.

37 PLRE IIIA, Fl. Ioannes 11, 627-635, cuya caída es expuesta por Procopio en Guerras 1.24-25. A. Cameron señala cómo únicamente tras la muerte de la emperatriz Justiniano permitió la vuelta de Juan de Capadocia del exilio, lo que supondría otra muestra del poder efectivo de Teodora (CAMERON 2000, 77-78).

38 Proc. Cesarea, Hist. Secr. 22.

39 Proc. Cesarea, Hist. Secr. 4.13.

40 Proc. Cesarea, Hist. Secr. 5.33-38; PLRE IIIB, Solomon 1, 1167-1177.

41 PLRE IIIB, Pegasius 1, 987-988.

42 Proc. Cesarea, Hist. Secr. 4. 21. Signes Codoñer 2000, 170.

43 Proc. Cesarea, Hist. Secr. 15.16-17.
} 
que la palabra "gobierno" aparece utilizada expresamente por el autor bizantino, debe sobreentenderse que realmente tuvo un papel activo en el mismo, lo habría ejercido de facto y además, siempre siguiendo la opinión del autor de la Historia Secreta, de un modo autoritario y abusivo.

En este sentido, y en primer lugar, es reseñable su capacidad de maniobra sobre los mandos de la esfera militar, lo que no deja de llamar la atención en un plano dominado por el elemento masculino y en el que la excepción de las amazonas, como señala Procopio, vendría a representar la anomalía de un grupo de mujeres que, ante la necesidad por la ausencia de hombres para garantizar su defensa, se habrían visto obligadas a incorporarse al mundo de la guerra. ${ }^{44} \mathrm{Al}$ hilo de lo anterior, Teodora hizo primero volver a Belisario a Bizancio junto a su "amiga" Antonina ${ }^{45} \mathrm{y}$, más adelante en el tiempo, convocó en la misma ciudad ante su presencia a unos cuantos comandantes del ejército romano, ${ }^{46}$ que acudieron a su orden y mando. Es decir, la emperatriz habría tenido la potestad suficiente como para desplazar generales por el Imperio, como demuestra el caso de Belisario, así como para convocarlos ante su presencia sin que hubiera mediado orden al respecto por parte del emperador (en el caso de que hubiera mediado, ésta no consta en la obra de Procopio).

Asimismo, y en cuanto a sus acciones en solitario, cabe destacar en segundo lugar el temor que sus actuaciones y posibles represalias generaban incluso entre los hombres más poderosos del Imperio. Procopio relata los castigos que la emperatriz infligía a sus enemigos, entre los que se encontraban: torturas -incluso a un senador, Teodosio-, ${ }^{47}$ exilios ${ }^{48}$ o la misma muerte, ${ }^{49}$ de tal suerte que todos, desde el pueblo hasta los sacerdotes, atemorizados ante sus acciones, cedian ante ella paralizados por el miedo y se lo concedían todo ${ }^{50}$ Según relata Procopio, Teodora llegó incluso a empalar a un alto cargo de la estructura del Imperio, el gobernador de la Cilicia Segunda, sin ningún motivo ${ }^{51}$ lo que daría buena muestra de que su autoridad en la corte estaba, realmente, por encima de la estructura territorial de poder del Estado romano, quedando, como todo parece indicar, en paralelo a la del emperador. A este respecto, y siguiendo con sus actuaciones ad libitum, no puede dejar de reseñarse que Teodora también provocó caídas sonadas, como las de Silverio o Juan de Capadocia, para las que contó con la ayuda de Antonina, ${ }^{52}$ o la de Prisco, que llevó a cabo en solitario. ${ }^{53}$

44 Proc. Cesarea, Guerras, 8.3.7-11.

45 Proc. Cesarea, Hist. Secr. 3. 4. En cuanto a la amistad entre ambas, ésta estuvo basada en un completo do ut des, pues Antonina ayudará a Teodora en empresas como la caída de Juan de Capadocia (Guerras 1.24-25), pero solo mientras reciba a cambio el favor de la emperatriz, como queda probado en Hist. Secr. 5.23, cuando a la muerte de ésta Antonina no dudará en romper los compromisos que había adquirido con ella. Al respecto de la caída de Juan de Capadocia vid. BRIDGE 1978, 109-121.

46 Proc. Cesarea, Hist. Secr. 4.6-7.

47 Proc. Cesarea, Hist. Secr. 3.7-30; PLRE IIIB, Theodosius 5b, 1291.

48 Vid. nota 47.

49 Proc. Cesarea, Hist. Secr. 15.20-23.

50 Proc. Cesarea, Hist. Secr. 3.26. Signes Codoñer 2000,166. El temor que generaban las acciones de Teodora aparece en repetidas ocasiones a lo largo de la Historia Secreta: 5.8-9; 5.26-27; 16.13.

51 Proc. Cesarea, Hist. Secr. 17.3.

52 Proc. Cesarea, Hist. Secr. 2.14; Signes Codoñer 2000, 148, notas 14 y 15

53 Proc. Cesarea, Hist. Secr. 16.7-10; PLRE IIIB, Priscus 1, 1051. 
Del mismo modo, y como se expondrá más adelante, Teodora pudo haber realizado intervenciones diplomáticas en la Italia ostrogoda y en Persia por su propia cuenta, ${ }^{54}$ lo que, como señala McCormick, la diferenciaría de otras emperatrices (Pulqueria, Ariadna, Sofía) cuya relevancia y poder habría sido reforzado por su existencia en periodos de transición política. ${ }^{55}$

Igualmente la emperatriz, "magnánima", del mismo modo que imponía castigos a sus enemigos, también concedía favores, incluso en el ámbito castrense, y valga como ejemplo de esto último el caso de Sergio, a quien eximió de recibir castigo alguno así como de que se le relevara de su mando, pese a las funestas consecuencias que sus prácticas habían generado en Libia para la causa romana. ${ }^{56}$

Por si lo anterior no fuera suficientemente explicativo de su posición al frente de la estructura que disponía la autoridad imperial, Procopio añade en el libro XV que Teodora utilizaba todo su poder-luego, efectivamente lo tenía-para hacer lo que le venía en gana dejándose llevar por la ira,${ }^{57}$ lo que de nuevo implicaría que, siempre desde el punto de vista del autor bizantino, aquella sí había ocupado una posición de poder en el Imperio, posición que además habría administrado de forma despótica.

En Bizancio la mujer, una vez casada, pasaba a ser considerada como una "asociada" a su marido. ${ }^{58}$ De este modo ella se asimilaba a él, y esta ausencia de autonomía la colocaba en una situación de inferioridad respecto del mismo. En el caso que nos ocupa, el de la emperatriz Teodora, puede afirmarse que nunca la palabra "asociada" habría sido tan precisa, aunque en este caso la asimilación no va a tener connotaciones negativas para ella sino todo lo contrario, y es que su poder se asimiló, en cierta medida, y como se ha expuesto, al de su marido, el emperador Justiniano. A tenor de los ejemplos presentados, y que han sido extraídos de la Historia Secreta de Procopio de Cesarea, se aprecia que el matrimonio, en numerosas ocasiones, tomaba las decisiones de forma conjunta, lo que indicaría que, a los ojos de este autor, ejercían un cogobierno del Imperio.

Más allá de los ejemplos expuestos anteriormente, cabe destacar que la Historia Secreta de Procopio, en el marco de la crítica a Teodora, ofrece cuatro pruebas más de la importancia que la emperatriz tuvo en la corte de su esposo y, por lo tanto, en la configuración de la imagen de su dinastía. Estas cuatro pruebas podrían ser resumidas en los siguientes términos: correspondencia, justicia, ceremonial y recursos financieros.

En primer lugar, y en cuanto al asunto de la correspondencia, resulta de especial interés una carta a la que Procopio alude en su obra y que fue remitida por Teodora a un individuo, Zaberganes, ${ }^{59}$ en un claro contexto político. En efecto, esta misiva se inserta en el contexto de las luchas entre romanos y persas en las campañas de los años 540 y 544 d.C., más concretamente en aquella que tuvo lugar en torno a la Lá-

54 Proc. Cesarea, Hist. Secr. 16.1-5.

55 Mccormick 2010, 147-148; un exhaustivo análisis de Pulqueria y del resto de las mujeres de la dinastía Teodosiana en Holum 1982.

56 Proc. Cesarea, Hist. Secr. 5.32.

57 Proc. Cesarea, Hist. Secr. 15.2-3. Signes CodoÑEr 2000, 168.

58 Beaucamp 1977, 162

59 PLRE IIIB, Zaberganes I, 1410; MaENCHEN-Helfen 1957, 283. 
zica, región situada al este del Mar Negro. En esta carta Teodora solicitaba al noble persa Zaberganes que persuadiera a su rey, el persa Cosroes ${ }^{60}$ para que llegase a un acuerdo de paz con el Estado romano. En la misma, la emperatriz se comprometía a conseguir que su marido le entregase grandes riquezas por su ayuda, puesto que, según habría escrito, aquel no haría nada sin contar con su opinión. ${ }^{61}$ Aunque no se conoce ninguna otra fuente que pueda corroborar la existencia de esta carta, que tan solo aparece reproducida por Procopio en su Historia Secreta,${ }^{62}$ de ser un documento que realmente existió, demostraría la implicación de la emperatriz en asuntos de calado político. Tanta habría sido dicha implicación que incluso se habría dirigido directamente y por escrito al bando enemigo durante un periodo de guerra en un intento de mediación para su posible solución. Asimismo, sus palabras finales, asegurando que su esposo, el emperador Justiniano, no haría nada sin contar con su opinión, también ofrecen una clara visión de la confianza que la emperatriz tenía de su propio poder, hasta el punto de poder ofrecer grandes riquezas al noble persa Zaberganes con la seguridad de que, ante la seriedad del asunto que se llevaba entre manos, podría cumplir con su promesa. Por lo tanto, esta carta resulta indicativa, siempre partiendo de la base de que realmente existió, del rol político que Teodora habría desempeñado en la estructura del Imperio. ${ }^{63}$

En segundo lugar, y en cuanto al asunto de la justicia, cabe simplemente desarrollar cuál era la situación general de las mujeres del mundo bizantino en este ámbito, para darse cuenta de que la situación de Teodora al respecto era completamente distinta y privilegiada. Las mujeres en Bizancio estaban sometidas a importantes restricciones en el campo de la justicia. Así, en general, sus intervenciones quedaban limitadas a la defensa de sus propios intereses y no podían actuar en un proceso judicial en nombre de un tercero, ni aunque fuese su marido, padre o hijo, a no se ser que estuvieran actuando en pro de su interés general. Las mujeres no tenían potestad para iniciar una investigación criminal, a no ser que estuvieran persiguiendo la violación de un derecho propio. Asimismo, y ante las restricciones, la única gran excepción es que la mujer estuviera actuando en pro del interés superior del Estado. ${ }^{64}$

En el caso de la emperatriz, los ejemplos que Procopio expone en su obra no dejan lugar a duda: Teodora participaba en la justicia y no lo hacía ni en su nombre ni en el del Estado. Son tres los casos expuestos por el autor bizantino en los que la emperatriz utiliza la justicia a su antojo, presentando y retirando cargos con el fin último, siempre mirando a través de la lupa de los ojos de Procopio, de alcanzar sus intereses personales al frente del Imperio; y cabe destacar que tan solo en uno de dichos casos utiliza el proceso, en teoría, para defenderse de un ataque personal. En primer lugar,

60 PLRE, Chosroes 1, 303-306.

61 Proc. Cesarea, Hist. Secr. 2.32-37.

62 Signes Codoñer 2000, 161.

63 Rol político que queda reforzado, en el contexto de apoyo al monofisismo por parte de la emperatriz, por la carta, esta vez dirigida a ella a través del rey árabe al-Harith, como consecuencia de la cual su esposo consagró a los monofisitas Jacobo Baradeus y Teodoro como metropolitanos de Edessa y Bostra, respectivamente; a este respecto vid. AlLEN 2000, 825.

64 Beaucamp 1977, 149; a este respecto véase la magnífica obra de AnJAVA 1996, 233-237, quien además indica que las mujeres tampoco podían actuar como testigos. 
el autor de Cesarea hace referencia a una carta que la emperatriz envió a Belisario; en ella, Teodora comunica al marido de Antonina su decisión de retirar los cargos que anteriormente habían sido interpuestos contra él. ${ }^{65}$ Los cargos a los que se refiere el escrito tienen que ver con las críticas que supuestamente habría recibido la emperatriz al sentirse ésta aludida ante el rechazo de algunos comandantes romanos a volver a tener un emperador como Justiniano. Este activismo anti-justinianeo habría surgido como reacción ante la enfermedad del propio emperador y el convencimiento de que moriría próximamente. La emperatriz, tal y como se desprende del texto y con total libertad, presentó cargos contra el comandante Belisario, cargos que a tenor de su carta estaría proponiendo eliminar. No obstante, y por el lenguaje utilizado en la redacción de su carta (he decidido retirar todas las acusaciones que pesan contra ti) ${ }^{66}$ la realidad es que no queda claro si con "todas las acusaciones", la emperatriz se refiere a eliminación de los cargos interpuestos por ella o también a los interpuestos contra Belisario por otras personas. En este caso, y si la emperatriz realmente tenía la potestad para eliminar los cargos interpuestos por otros individuos, no queda duda de que su poder en el plano jurídico no habría sido nada desdeñable.

A esta carta enviada a Belisario, y continuando con la relación que se establece entre Teodora y la justicia en la Historia Secreta de Procopio de Cesarea, habría que añadir el caso de Basiano ${ }^{67}$ En el contexto de unas críticas vertidas por éste contra la emperatriz, ésta emprendió, libremente y sin mediación de su marido (por lo que se deduce del texto), tres acciones contra él. En primer lugar, le envió a un magistrado del pueblo; en segundo lugar, le advirtió mediante dicho magistrado de que los cargos que iba a presentar contra él no iban a ser de calumnias sobre ella misma, sino de pederastia y, finalmente y en tercer lugar, tras castigarlo físicamente ordenó su ejecución sin mediar juicio alguno. No sorprende tanto que tuviera la potestad de enviar un magistrado para presentar cargos contra Basiano, como el hecho de que dichos cargos no tuviesen que ver ni con la violación de un derecho propio ni con la defensa del interés superior del Estado. Teodora, saltándose las prohibiciones y limitaciones de la participación del elemento femenino en un proceso judicial, actúa contra Basiano con las armas que solo un hombre podría haber utilizado. Además, y siguiendo el texto de Procopio, llegará a ordenar la muerte de Basiano obviando el paso previo del juicio, lo que resulta indicativo de su libertad de acción -y castigo- sobre sus súbditos.

Finalmente, cabe destacar en el ámbito judicial cómo la emperatriz utilizó también su autonomía para colaborar con mujeres adúlteras en procesos contra sus maridos. Un asunto que tampoco tenía que ver con la defensa personal por la violación de un derecho propio ni con el interés superior del Estado, y en el que Teodora ejercía de abogado de aquellas mujeres, que acababan incoando procesos contra sus maridos, según Procopio, por hechos inexistentes. ${ }^{68}$ Tal debió de ser su libertad de acción en el

\footnotetext{
65 Proc. Cesarea, Hist. Secr. 4.26-29.

66 Proc. Cesarea, Hist. Secr. 4.27. Signes Codoñer 2000, 171.

67 Proc. Cesarea, Hist. Secr. 16.18-22.

68 Proc. Cesarea, Hist. Secr. 17.24. Signes Codoñer 2000, 257-258.
} 
campo judicial que Moorhead no descarta que hubiera jugado un papel fundamental incluso en el marco de las tareas legislativas. ${ }^{69}$

Como puede apreciarse ante estos ejemplos, la libertad de acción de Teodora en un campo tan importante como el de la justicia, y el hecho, como se verá más adelante, de que incluso los magistrados debieran postrarse a sus pies, demuestran, una vez más, su situación privilegiada al frente de los asuntos relevantes desde el punto de vista político-decisorio del Imperio romano.

Tras la justicia, y en tercer lugar, llama la atención el ceremonial que envuelve a la emperatriz y que supone una novedad con respecto a la tradición que había imperado en la corte imperial hasta el momento. A diferencia del protocolo, que es la norma, el ceremonial viene a ser la forma de un acto, del tratamiento a una autoridad o a un individuo determinado. El ceremonial es, diríamos hoy, la etiqueta que rodea un acto, y viene a simbolizar aquello que los creadores del mismo pretenden transmitir al observador. El ceremonial es una representación plástica y visual del poder de sus protagonistas. ${ }^{70}$

En el caso de la corte de Justiniano, y a tenor del texto de Procopio de Cesarea, los cambios en la forma, en el mencionado ceremonial, transmiten dos ideas fundamentales: una, que la emperatriz debe recibir el mismo tratamiento que el emperador, incluso por parte de los miembros del senado y también de aquellos individuos que ostentasen la dignidad del patriciado y, dos, que las diferencias entre quien ostenta el poder y quien no lo ostenta, es decir, entre el matrimonio imperial y el resto de la población -incluidos los magistrados y los sacerdotes, como se expondrá- deben quedar más claras que nunca.

En cuanto a la incorporación de Teodora al ceremonial, señala Procopio que, antes del reinado de Justiniano, cuando el senado rendía pleitesía al poder imperial lo hacía únicamente ante el emperador, agachando la cabeza de modo que éste pudiera besarle la frente; acto seguido el resto de asistentes, y tras realizar una breve genuflexión, se retiraba de la sala donde tenía lugar el acto. ${ }^{71}$ A partir del reinado de Justiniano, sin embargo, y siempre según el relato de Procopio, los senadores y patricios que desearan rendir pleitesía al poder imperial debían dirigirse tanto al emperador Justiniano como a su esposa, la emperatriz Teodora. Asimismo, añade el autor bizantino, el ceremonial, es decir, la forma de tal encuentro habría cambiado notablemente, pues ahora aquellos debían tumbarse en el suelo y besar los pies de la pareja consorte antes de volver a ponerse de pie. ${ }^{72}$ Esta nueva forma de simbolizar la diferencia entre quienes ostentaban el poder, Justiniano y Teodora -en lo que parece, de nuevo, un claro cogobierno entre ambos- y quienes, por el contrario, debían rendirles pleitesía, deriva, según diversos autores, del reinado de Diocleciano. ${ }^{73}$ Para Stern, el significa-

69 Moorhead 1994, 38-39.

70 Resulta interesante a este respecto la lectura de Vilarrubias 2005, especialmente 19-30.

71 Proc. Cesarea, Hist. Secr. 30.21-22.

72 Proc. Cesarea, Hist. Secr. 30.23-25.

73 H. Stern y O. Treitinger consideran que la adoratio deriva de Diocleciano (STERN 1954, 184-185; TReitinger 1956, 84-85); por el contrario M. Alföldi considera que provendría del siglo I d.C. y del marco de las monarquías helenísticas (ALFöLDI 1934, 1-25 y 46-72); finalmente W. T. Avery plantea una posición intermedia, para él de las dos partes de la adoratio, genuflexión y beso, la primera ya era oficial antes 
do de la ceremonia de la adoratio implicaría que a partir de Diocleciano el emperador habría pasado a ser considerado como sagrado; así, Diocleciano marcaría con esta ceremonia un punto de inflexión entre el constitucionalismo romano de Occidente y el nacimiento de la noción del derecho divino de los reyes que se haría fuerte en Oriente. ${ }^{74}$ Sin embargo, y si aquella adoratio marcaría un antes y un después en la visión plástica del poder imperial, se podría afirmar que también los cambios introducidos bajo el gobierno de Diocleciano pueden ser dignos de ser considerados revolucionarios desde el mismo punto de vista visual y simbólico. De este modo, si hasta ahora el beso se realizaba en el manto púrpura del emperador o en sus rodillas, ahora se llevará a cabo en sus pies, un lugar que rebaja todavía más la condición de sus súbditos, que descienden un escalón más hacia su condición de siervos plenos; y también, como novedad reseñable, aquellos besarán los pies no solo del emperador, sino también los de su esposa la emperatriz Teodora. A este respecto cabe añadir que también los magistrados debían prosternarse ante ella y besar el empeine de sus dos pies, ${ }^{75}$ una muestra más que debería añadirse a su poder ante el plano judicial, que debía venerarla.

Junto con la incorporación de Teodora a un ceremonial reservado, hasta el momento, a los emperadores, parece que el poder del matrimonio imperial va a quedar más distanciado que nunca, por encima -y de un modo mucho más evidente desde el punto de vista estético- del resto de individuos del Estado romano; más distanciado incluso sobre el estatus y simbolismo representado por los magistrados, que pasan ahora a ser llamados siervos ${ }^{76}$ quedando así equiparados, pese a su posición, con los individuos más humildes del Imperio. Asimismo, las diferencias formales se ampliaron, también, mediante la incorporación, en cuanto al tratamiento de Justiniano y Teodora, de los términos "señor" y "señora" a los de "emperador" y "emperatriz" que debían ser utilizados, incluso, por los sacerdotes. ${ }^{78}$

De este modo, y a tenor del nuevo ceremonial impuesto en la corte de Justiniano, puede considerarse que también Teodora habría alcanzado la condición de sagrada, con lo que se la puede considerar una integrante más de la monarquía de derecho divino. No obstante, y ante lo expuesto, parece claro que debe ser considerada no como una mera consorte, sino como una esposa con el protagonismo suficiente para ser autorizada a recibir los mismos honores que su esposo, el divino Justiniano. A favor de esta sacralización, y sin abandonar la Historia Secreta, el mismo Procopio destaca que incluso los senadores la adoraban como si fuera un dios. ${ }^{79}$

de Diocleciano y la segunda habría sido introducida por él (Avery 1940, 66-80). Al respecto del culto al emperador antes de Diocleciano vid. también Millar 1973.

74 STERN 1954, 189.

75 Proc. Cesarea, Hist. Secr. 15.13-16.

76 Proc. Cesarea, Hist. Secr. 30.26.

77 Proc. Cesarea, Hist. Secr. 30.25.

78 Proc. Cesarea, Hist. Secr. 10.7.

79 Proc. Cesarea, Hist. Secr. 10.6; siguiendo a M ${ }^{\mathrm{a}} \mathrm{J}$. Hidalgo de la Vega, esta sacralización de la emperatriz debe ser entendida como una continuidad en la construcción de la imagen de la emperatriz cristiana con respecto a las emperatrices del Alto Imperio, con lo que la posición Teodora en este punto no supondría una ruptura con los siglos precedentes, sino una potenciación en la visibilidad y relevancia de su imagen, en 
Finalmente, y en lo que respecta a Teodora y su relación con los recursos financieros del Estado, cabe destacar cómo habría tenido la potestad de disponer de dinero para finalidades tales como la de pagar a persas y otros bárbaros, ${ }^{80}$ tal y como se deduce del texto de Procopio de Cesarea, de modo autónomo con respecto de su esposo. También habría financiado viajes a sus protegidos ${ }^{81}$ requisado fortunas de particulares ${ }^{82}$ en nombre de mismísimo emperador, a quien, cual empleada del fisco, entregaba el botín. ${ }^{83}$

Así pues, por lo que parece, y a tenor de los ejemplos ofrecidos por Procopio en su Historia Secreta, la emperatriz actuaba con gran libertad incluso en campos vedados para las mujeres, como el militar y el judicial. Tuvo también un lugar preferente en el ceremonial y acceso al tesoro imperial, así como innumerables bienes y grandes riquezas. ${ }^{84}$ Teodora ostentó efectivamente una posición relevante, junto con su esposo, al frente de la toma de decisiones en el marco del gobierno imperial. Todas las pruebas aportadas en la Historia Secreta de Procopio de Cesarea parecen indicar que la emperatriz participó, de facto, en su administración.

Dejando el texto de la Historia Secreta, aunque sin abandonar la obra de Procopio, cabe también destacar el discurso que este autor pone en boca de la emperatriz Teodora en el libro I de De Belliss. ${ }^{85}$ En el contexto de la revuelta de Niká, que tuvo lugar en Constantinopla en 532 d.C., ${ }^{86}$ la situación para Justiniano se complicó notablemente. Una discusión intrascendente entre dos facciones del circo, los verdes y los azules, acabó convirtiéndose en una gran revuelta popular, que fue aprovechada por aquellos que querían derrocar al emperador Justiniano, entre otros motivos, por la subida de los impuestos. En este contexto de tensión, la usurpación del trono imperial por parte de Hypatius hacía que el gobierno de Justiniano se tambaleara, tanto, que incluso este último se planteó huir de la ciudad. Como señala Moorhead, la situación era desesperada, el gobierno había perdido el control de la capital imperial y el sobrino del que había sido un emperador popular, Anastasio I, se había rebelado abiertamente. ${ }^{87}$ En estas circunstancias de incertidumbre en el gobierno del emperador Justiniano y en un momento en el que el elemento masculino del poder imperial, el propio emperador, estaría haciendo gala de una cierta cobardía, como se desprende del texto de Procopio, la acción de la emperatriz serviría para infundir la valentía y el coraje que se presupone a los más altos dignatarios. Se podría decir que su actuación habría sido, siempre en función del texto del autor bizantino, la que habría permitido solucionar la situación. Ante las diferentes opiniones del emperador y su corte en palacio acerca de

clave cristiana (HIDALGO DE LA VEGA 2010, 205-206); para el conocimiento de las emperatrices altoimperiales resultan especialmente interesantes las obras de Mirón Pérez 1996; Burns 2007 e Hidalgo de la Vega 2012.

80 Proc. Cesarea, Hist. Secr. 30.24.

81 Como Jacobo Baradeus, a quien financió viajes en las provincias de Siria y Asia Menor durante años, KenNedy 2000, 594.

82 Proc. Cesarea, Hist. Secr.16.20; 4.31, entre otros muchos ejemplos.

83 Proc. Cesarea, Hist. Secr. 4.31.

84 Proc. Cesarea, Hist. Secr. 9.31-32.

85 Proc. Cesarea, De Bellis, 1.24.32-37.

86 Al respecto de la misma Evans 2005, 15-20; MCCoRnick 2000, 144, 150; para fuentes y bibliografía sobre su origen, CAMERON 2000, 71, nota 53.

87 MoORHEAd 1994, 46. 
si debían o no huir de Constantinopla, el autor bizantino hace hablar a la emperatriz, ${ }^{88}$ en una alocución que vendría a ser una declaración de intenciones acerca del valor de la resistencia y la dignidad real. Para alguien que ha ocupado la dignidad real es insoportable ser un fugitivo ${ }^{89}$ señala Teodora según el texto reproducido por Procopio; y añade nunca me separaré de la púrpura y no viviré el día en que aquellos que encuentro dejen de dirigirse a mi como la emperatriz. Si es tu deseo, emperador, salvarte, no hay problema. Para los que tenemos dinero, alli está el mar y aquí los botes. Sin embargo, considera si una vez salvado no habrías cambiado aquella seguridad por la muerte $;{ }^{90} \mathrm{y}$ concluye con una frase que todavía resalta más el coraje que de la emperatriz quiere transmitir Procopio en mi caso, estoy de acuerdo con un antiguo que decía que la realeza es una buena mortaja para un entierro. ${ }^{91}$ Es decir, en el discurso la emperatriz muestra su arrojo: prefiere morir como emperatriz que vivir como fugitiva. ${ }^{92}$

Procopio está representando a una Teodora que domina la situación de crisis que atraviesa el gobierno del Imperio, y que es capaz de mantener el coraje ante unos hombres, entre los cuales se sitúa el propio emperador, que pese a su dignidad y posición en el Imperio, no son capaces de mantener una postura valiente propia de su estatus. Ante este texto, el problema radica en que no puede ser probado por ninguna otra fuente, pues solo aparece en el citado De bellis. Esta realidad y el hecho, como señala Moorhead, de que muy posiblemente el autor bizantino no habría presenciado la escena ${ }^{93}$ parecen indicar que el discurso habría sido falso e inventado por él mismo. ${ }^{94}$

No obstante, sea o no verdadero este discurso, su importancia radica en que, pese a poder no ser cierto en su contenido, vendría a representar la realidad política que Procopio percibía en el Imperio: un emperador y una corte débil y asustadiza, y una emperatriz que, ante las dificultades, era capaz de tomar las riendas de la situación y mantener la dignidad de su posición social -posición que, por otra parte, habría

88 J. B. Bury señaló que Procopio es fundamental para conocer la revuelta desde el punto de vista de palacio, contraponiéndolo a Malalas, quien la habría mostrado desde el punto de vista del vulgo (BURY 1897, 93-94). En cuanto a la fecha concreta del discurso, éste se produjo el 18 de enero de 532 d.C. (BURY 1987, 119; Greatrex 1997, 73).

89 Proc. Cesarea, De Bellis, 1.24.35

90 Proc. Cesarea, De Bellis, 1.24.36-37.

91 Proc. Cesarea, De Bellis, 1.24.37.

92 Lo que haría, en palabras de M. Diehl, que su ambición se convirtiera en heroísmo (DieHL 1937, 136137). Como señala J. A. S. Evans, Teodora aparece en la obra de Procopio como heroína y como tirana al mismo tiempo, otra de las ambigüedades a las que, según su opinión, acostumbra Procopio al lector en sus obras (EvANS 1984, 280-282).

93 MoOrhead 1994, 46-47.

94 A este respecto cabe destacar la opinión de Evans, quien considera que tampoco habría sido imposible que ella lo hubiera pronunciado y que Procopio hubiera conocido su discurso porque a él se lo hubiera narrado Belisario, quien lo habría escuchado en vivo y en directo (EvANs 1984, 282). En este sentido también destaca, por contraria, la opinión de E. Fischer quien, ante la imposibilidad de probar la veracidad de buena parte de las afirmaciones y documentos aportados por Procopio en su obra, duda de la autenticidad de los mismos. Para esta investigadora Procopio hace del rumor su fuente y, apelando a la lascivia y al rencor de sus lectores, demuestra una admirable "ingenuidad", que no integridad, como historiador (FISCHER 1978, 274, 276-277). 
adquirido gracias a su matrimonio con Justiniano-.${ }^{95}$ Dado que la cita real a la que las palabras de Teodora hacen referencia, sería la tiranía es una buena mortaja para un entierro y no la monarquía..., ${ }^{96}$ Moorhead propone que lo que Procopio estaría manifestando con el texto que pone en boca de Teodora es su disconformidad con la misma y quizás también con su marido. ${ }^{97}$ La opinión de este investigador implicaría que Procopio estaría tachando a Teodora de tirana. Ante esta posibilidad, si la emperatriz actuó como una tirana es porque tenía el poder, tenía la potestad, para hacerlo. Luego, sea o no literalmente cierto el contenido del discurso que dice recoger Procopio, la realidad es que el hecho de que se le atribuya a ella el tomar las riendas de la crisis, resulta de lo más indicativo, de nuevo, de cuál pudo ser su actitud en la corte y en el gobierno de su esposo, el emperador Justiniano.

Merece también la pena hacer alusión al papel que Teodora habría jugado en la construcción de edificaciones públicas en el marco del gobierno de su esposo. En este sentido Procopio, en otra de sus obras, De aedificiis, muestra las edificaciones en cuya realización ella tomó parte activa. A partir del siglo IV d.C., los cambios en el gobierno del Imperio derivados del ascenso del cristianismo afectaron a las actividades de patrocinio en la esfera secular e, indirectamente, ampliaron las oportunidades para el mecenazgo en proyectos religiosos para ciertos grupos de población que hasta el momento habían ocupado un lugar marginal en las esferas de poder. Uno de los grupos que aprovecharon este incremento del patrocinio religioso fue el de las mujeres, hasta ahora excluidas de toda situación de poder. Y es que aunque la Iglesia no deseaba asimilarlas en su jerarquía, y no lo hizo, sin embargo sí necesitaba de sus recursos económicos, lo que hizo que les permitiera actuar como mecenas en proyectos de carácter religioso. Como señala Clark, el mecenazgo religioso se convirtió, para las mujeres, en un modo de ganar reconocimiento así como, ocasionalmente, poder; aunque no lo harían, pese al ámbito de sus empresas, como "priests" sino como "patrons", es decir, no como sacerdotes sino como patrocinadores. ${ }^{98}$

En este contexto de patrocinio femenino, sin duda las más notables donantes de fondos a la Iglesia fueron las mujeres de la casa imperial, quizás inspiradas por el ejemplo de Helena y sus fundaciones en Palestina. ${ }^{99} \mathrm{Al}$ respecto cabe destacar las edificaciones iniciadas por Teodora, y que Procopio expone en su obra, en colaboración con su esposo Justiniano. El autor bizantino la vincula al emperador en las pinturas del pórtico denominado Chalkê, que daba entrada al palacio imperial, ${ }^{100} \mathrm{y}$ la sitúa también en una imagen que la ciudad de Constantinopla le habría dedicado en agradecimiento, según parece, por la construcción de unos baños situados en el este de la capital; ${ }^{101}$ dos obras, en este caso, de carácter civil. Si bien en el primero

95 Proc. Cesarea, Hist. Secr. 9.30-32; para los aspectos legales del mismo DauBe 1967, 380-399.

96 Evans 1984, 280-281; ID. 2002, 45-47.

97 Véase nota 93.

98 Clark 1990, 253-254.

99 Eus., VC III, 42-45; Teodoreto, Hist. Eccl. I, 18; Sócrates, Hist. Eccl. I, 17; Sozomeno, Hist. Eccl. II, 1-2; Rufino, Hist. Eccl. X, 7. A este respecto véase Holum 1990 y Hunt 1984, en especial 28-54. Una excelente síntesis de la implicación de las mujeres imperiales en la Iglesia en CAMERON 1993, 67-69.

100 Proc. Cesarea, Aedif. 1.10.17; MANGO 1959.

101 Proc. Cesarea, Aedif. 1. 11.8. 
de los dos casos no se hace ninguna alusión específica al papel que Teodora habría tenido en la edificación del pórtico, la presencia de su imagen a la entrada del palacio imperial, recibiendo junto con la de su esposo al visitante, resulta indicativa de que su figura debió de ocupar un lugar relevante en cuanto a la representación plástica del poder político el Estado. ${ }^{102}$ El visitante debía saber quien regía en el palacio y, por lo tanto, en el Imperio. En el segundo caso, pese a que Procopio señale que la edificación fue obra del emperador Justiniano, la estatua que la ciudad ofrece a la emperatriz en agradecimiento hacia la misma por los baños edificados, implicaría que ésta también habría tenido alguna participación en dicha edificación. Finalmente, la construcción por parte de ambos de un hospicio temporal para personas en dificultades y de un convento para mujeres que se habían visto abocadas a la prostitución por su precaria situación económica, construcción esta última de carácter religioso, vendrían a unirse a las edificaciones que la pareja imperial habría llevado a cabo conjuntamente. ${ }^{103} \mathrm{Si}$ bien Procopio no hace referencia a ninguna otra obra en cuya construcción hubiese tomado parte, la realidad es que la emperatriz aparece asociada a su esposo en muchas otras construcciones de índole religiosa. ${ }^{104} \mathrm{Su}$ participación en las mismas en calidad de mecenas junto a su marido vendría a representar, por una parte, su capacidad para participar en las políticas públicas del Imperio, entre las cuales deben integrarse las edificaciones imperiales. Por otra parte, tal y como parece descrito por Procopio, las dos obras de mayor envergadura, el hospicio y el convento para mujeres, parecen haber sido la solución a dos problemas por los que atravesaba la ciudad de Constantinopla: el del alojamiento de quienes en busca de audiencia con el emperador se aglomeraban en la capital -en las más de las ocasiones sin recursos suficientes para subsistir en la ciudad-, y el de las mujeres que se veían abocadas a la prostitución debido a sus problemas financieros. Su participación en tales edificaciones probaría su decidida participación en la resolución de los problemas del Imperio. Es decir, Teodora no solo habría ocupado una posición de relevancia política en el Estado romano junto a su esposo, sino que además habría utilizado este poder efectivamente, en este caso concreto en forma de construcción; una construcción que habría implicado, además, un gasto para el tesoro imperial.

Ante las reticencias que pueda provocar el hecho de juzgar a un personaje histórico bajo el prisma de una sola fuente, Procopio en este caso, y ante la posibilidad de que dicha fuente distorsione la realidad y ofrezca al historiador una imagen errónea del personaje a estudiar, merece la pena analizar otras fuentes que describan el objeto de estudio para analizar hasta qué punto la visión de la fuente principal es o no objetiva. En nuestro caso, el ejemplo proporcionado por el papiro del Cairo al que

102 Sobre la representación de Teodora, y como muestra de su relevancia política, cabe mencionar aquí los mosaicos de la basílica de San Vital, en Rávena, en los que aparece representada en el mismo plano que su esposo. A este respecto resultan de interés BARBER 1990 y CLARK 1993, especialmente 106-110. Acerca de las representaciones visuales del poder de las emperatrices en época tardoantigua, Marcos SÁnchEZ 1996.

103 Proc. Cesarea, Aedif. 1.11.27; 1.9.1-10.

104 L. Brubaker señala la presencia del monograma de la emperatriz en numerosos edificios de índole religiosa, como las iglesias de Santa Sofía y San Sergio en Constantinopla, y explica el hecho de que Procopio no haga referencia a Teodora por el deseo de mantener el rol prioritario en cuanto a las construcciones del elemento masculino de la pareja (BRUBAKER 2005, 432). 
se hará referencia a continuación, vendría a confirmar el papel relevante que la emperatriz Teodora habría desempeñado en el cogobierno del Imperio y que, como se ha expuesto anteriormente, aparece desarrollado en la obra de Procopio. El texto del papiro vendría a confirmar su participación efectiva en la vida pública del imperio, pues muestra a una Teodora que había asumido el patrocinio de la población egipcia de Aphrodito. En el mismo, los habitantes de la citada población pedían ayuda a la casa divina de la emperatriz Teodora, ${ }^{105}$ ante los abusos del oficial encargado de la administración financiera sobre la región (aproximadamente el antiguo nomo). Dirigiéndose directamente a la emperatriz, se describían a sí mismos "como clientes de la autoridad ducal y de los oficiales de la emperatriz". ${ }^{106}$ Años después, ya muerta Teodora, los habitantes de Aphrodito volvieron a solicitar la protección imperial ante los reiterados abusos del citado oficial de la administración, que no habrían cesado; esta vez la petición fue dirigida al emperador, quien habría pasado a ser el protector de la población, ocupando el compromiso otrora desempeñado por su esposa. ${ }^{107} \mathrm{El}$ hecho de que Teodora fuera patrona o evergeta de aquella población y de que sus habitantes reconocieran tal patrocinio, pues acudieron ante ella a solicitar su ayuda cuando la necesitaron, es una muestra más de su participación en la vida pública del Imperio y de su capacidad política; una capacidad, como se apunta, reconocida por la sociedad civil del momento. Asimismo, el hecho de que a su muerte fuera el propio emperador Justiniano y no un alto funcionario de la administración imperial quien se hiciera con la responsabilidad que previamente había desempeñado Teodora, implicaría que aquel puesto era realmente relevante, o al menos lo suficientemente relevante como para que fuese ocupado por el propio emperador y no por cualquier otro alto cargo del Estado romano. El papiro del Cairo vendría a indicar que incluso habitantes de un remoto lugar del imperio como Aphrodito reconocían y valoraban el protagonismo político de la emperatriz. ${ }^{108}$ Ante esta realidad cabe plantearse cuán importante debió de ser su protagonismo en la corte de Bizancio para que los habitantes de un lugar tan lejano de Constantinopla como una población del Egipto medio fueran conscientes del mismo y le solicitasen su ayuda. Y a este respecto cabe destacar que quizás este conocimiento que las gentes del Imperio tenían de la emperatriz, habría sido la causa de que ésta no fuera representada en las acuñaciones monetales, como sí lo fueron emperatrices como Helena, Eudoxia o la futura Sofía, sobrina de Teodora; por lo que su falta de representación no habría tenido que implicar, como supone Evans, que aquella hubiera ostentado un poder de "segunda mano". ${ }^{109}$

Más allá de la obra de Procopio, al ejemplo del papiro del Cairo habría que unir las impresiones de los autores bizantinos Juan el Lidio y Zonaras, quienes narran cuál habría sido el poder de la emperatriz Teodora en la corte. Así, Juan el Lidio expo-

105 Al respecto de la divina domus, Zingale 1984-85.

106 P. Cairo Masp. III 67283, en el que aparecen como firmantes miembros del estamento eclesiástico de la población, así como terratenientes, campesinos y diversos artesanos y profesionales de la misma; véase KEENAN 2000, 635.

107 BeLl 1944, 31; HARDY 1968, 38, se plantea cuánta atención habría recibido la población de la emperatriz.

108 BRUBAKER 2005, 438.

109 Evans 2002, 25-30, en especial 26-27. 
ne que efectivamente habría correinado con Justiniano; ${ }^{110}$ mientras Zonaras todavía le otorga más protagonismo político, asegurando que su poder, en un régimen que podría describirse como diarquía y no como monarquía, incluso habría superado al del propio emperador. ${ }^{111}$ Ante estas declaraciones -y aunque cabe destacar que, en opinión de Moorhead, el hecho de que Teodora no pudiera hacer prevalecer su causa religiosa a favor del monofisismo implicaría que su poder habría sido más limitado de lo que parece- $-^{112}$ no habría que desechar la idea de su predominio público en la corte y de que su opinión política debió ser tenida en cuenta por quienes la rodeaban, tal y como se tenía en cuenta la de su esposo el emperador.

Como se expuso al comienzo del artículo, Teodora, de haber sido una mera emperatriz consorte sin un papel activo en la política del Imperio, no habría sido utilizada por Procopio para denigrar a Justiniano y a la casa imperial, finalidad que parece perseguir su Historia Secreta. Y es que para Procopio no habría habido nada peor que un marido débil de carácter, Justiniano, que no supiera mantener a su esposa, Teodora, bajo control. ${ }^{113} \mathrm{Al}$ igual que Tácito y Casio Dión escribieron acerca de las malas emperatrices de la dinastía julio-claudia para simbolizar el desorden del Estado bajo sus elementos masculinos, ${ }^{114}$ Procopio critica a la "mala y despótica" Teodora como prueba del desorden del Estado de Justiniano. A Procopio no le gustaban las mujeres en el poder, no le gustaba gente de baja cuna que se daba aires de grandeza y acabó rechazando también a todo aquel que estuviera estrechamente relacionado con Justiniano; ${ }^{115}$ Teodora habría cumplido sobradamente estas tres características. Las críticas que recibe por parte de Procopio, junto con la confirmación de fuentes externas como el papiro del Cairo o los testimonios algo tardíos de autores como Juan el Lidio o Zonaras, vendrían a demostrar que, efectivamente, Teodora ocupó una situación relevante dentro del ámbito del gobierno en el Imperio de su esposo, hasta el punto de poder hablar de un evidente cogobierno de ambos. Fuera Teodora "un accidente de la historia o una mujer de extraordinaria habilidad", ${ }^{116}$ la realidad es que en Bizancio "las estructuras imperiales requerían de emperatrices" 117 y a tenor del texto de Procopio la estructura liderada por Justiniano requirió, especialmente, la suya propia. Como señala James, en la sociedad bizantina la emperatriz era una contradicción en sí misma, tenía cuerpo de mujer, lo que la incapacitaba para el poder, pero a la vez un cuerpo político como parte de la jerarquía del Estado, lo que le daba un verdadero poder político. ${ }^{118}$ Un poder de cuyo uso, según la obra de Procopio, la esposa del emperador Justiniano fue un buen ejemplo.

110 Juan Lydus, Poderes, 3.69.

111 Zonaras, Epit., 14.6; Evans 2002, 26.

112 MoorheAD 1994, 40; al respecto de los conflictos religiosos bajo el gobierno de Justiniano véase Schubart 1943, 184-194; Evans 2002, 40-45 y Garland 1999, $23-29$.

113 Brubaker 2004, 99; como señala A. Cameron, lo peor de Justiniano y Belisario, según el texto de Procopio, era su dependencia de sus esposas (CAMERon 1985, 71).

114 FisChLER 1994, 128.

115 Cameron 1985, 81-83.

116 LaIOU 1981, 250.

117 HERRIN 2000, 34-35.

118 Tac., Ann. 12.7, 13.45; Cas. Dio, Hist. Rom., 60.14.1, 61.7.1-3; JAMES 2001, 164-166. 
Ante lo expuesto, y para finalizar, cabe destacar que las duras críticas recibidas por Teodora en la obra del autor bizantino son un claro ejemplo de la importancia de lo femenino en la construcción de la imagen de la casa imperial, que podía quedar engrandecida o ensombrecida tanto por las acciones de su elemento masculino como por aquellas llevadas a cabo por el elemento femenino de la misma. Un elemento que también decidía y actuaba, con mayor o menor rigor según el prisma con el que se observen sus actos, desde el vértice de la pirámide de poder representada por el Estado romano de Bizancio.

\section{Bibliografía}

AlfÖLDI, M. (1934): "Die Ausgestaltung des monarchischen Zeremoniells am römischen Kaiserhof", Römische Mitteilungen XLIX, 1-25 y 46-72.

Allen, P. (2000): "The definition and enforcement of orthodoxy", [en] A. Cameron - R. Ward-Perkins - M. Whitby (eds.), The Cambridge ancient history. Vol.14, Late antiquity: empire and successors, AD 425-600, Cambridge University Press, Cambridge, 811-834.

Anjava, A. (1996): Women and Law in Late Antiquity, Clarendon Press, Oxford.

Avery, W. T. (1940): "The adoratio purpurae", Memoirs of the American Academy in Rome XVII, 66-80.

BARBER, C. (1990): “The imperial panels at San Vitale: a reconsideration”, BMGS 14, 19-42.

BeAuCAmp, J. (1997): “La situation juridique de la femme à Byzance", Cahiers de Civilisation Médiévale 20, 145-176.

BeLl, H. (1944): “An Egyptian Village in the Age of Justinian”, JHS 64, 1944, 21-36.

Bridge, A. (1978): Theodora: Portrait in a Byzantine Landscape, Cassel, London.

Browning, R. (1987): Justinian and Teodora, Thames and Hudson, London.

BRUBAKER, L.

(2004): "Sex, lies and textuality: the Secret History of Prokipios and the rethoric of gender in sixth-century Byzantium", [en] L. Brubaker - J. Smith (eds.), Gender in the Early Medieval World, Cambridge University Press, Cambridge.

(2005): "The Age of Justinian, Gender and Society", [en] M. Maas (ed.), The Cambridge companion to the Age of Justinian, Cambridge University Press, Cambridge, 427-447.

Burns, J. (2007): Great Women of Imperial Rome. Mother and Wives of the Caesars, Routledge, London.

Bury, J. B. (1987): “The Nika Riot”, JHS 17, 92-119.

Cameron, A.

(1985): Procopius and the Sixth Century, London, Duckworth.

(1993): The Mediterranean World in Late Antiquity, AD 395-600, Routledge, London.

(2000): "Justin I and Justinian", [en] A. Cameron - R. Ward-Perkins - M. Whitby (eds.), The Cambridge ancient history. Vol.14, Late antiquity: empire and successors, AD 425600, Cambridge University Press, Cambridge, 63-84.

Clark, E. A. (1982): Jerome, Chrysostom, and Friends, The Edwin Mellen Press, New YorkToronto. 
Clark, G. (1993): Women in Late Antiquity, Pagan and Christian Life-styles, Clarendon Press, Oxford.

Daube, D. (1967): “The marriage of Justinian and Theodora. Legal and Theological Reflexions", Catholic University Law Review 16, 380-399.

Dient, M. (1937): Théodora. Impératrice de Byzance, E. de Boccard, Paris.

Evans, J. A.

(1984): "The Nika rebellion and the Empress Teodora", Byzantion 54, 280-282.

(2002): The Empress Theodora: Partner of Justinian, University of Texas Press, Austin.

FISCHER, E. (1978): “Theodora and Antonina in the Historia Arcana : History and/or Fiction?", Arethusa 2, 253-280.

FISCHLER, S. (1994): "Social Stereotypes and Historical Analysis: The Case of the Imperial Women at Rome", [en] L. J. Archer - S. Fischler - M. Wyke (eds.), Women in Ancient Societies, An Illusion of the Night, Basingstoke, Macmillan, 115-133.

GARLAND, L. (1999): Byzantine empresses, Routledge, London-Nueva York.

Greatrex, G. (1997): “The Nika Riot: A Reappraisal”, JHS 117, 60-86.

Hardy, R.E. (1968): “The Egyptian Policy of Justinian”, Dumbarton Oaks Papers 22, 21-41.

HeAther, P. (2010): Emperadores y barbaros. El primer milenio de la historia de Europa, Crítica, Barcelona.

Herrin, J. (2000): “The Imperial Feminine in Byzantium”, Past and Present 169 (nov.), 3-35.

Hidalgo de la Vega, Ma . J.

(2010): "Emperatrices paganas y cristianas: poder oculto e imagen pública", [en] A. Domínguez Arranz (ed.), Mujeres en la Antigüedad Clásica. Género, Poder y Conflicto, Sílex Ediciones, Madrid, 185-210.

(2012): Las emperatrices romanas. Sueños de púrpura y poder oculto, Ediciones Universidad de Salamanca, Salamanca.

Holum, K.

(1982): Theodosian Empresses. Women and Imperial Dominion in Late Antiquity, University of California Press, Berkeley-Los Angeles-London.

(1990): "Hadrian and St. Helena: Imperial Travel and the Origins of Christian Holy Land Pilgrimage", [en] R. Ousterhout (ed.), The Blessings of Pilgrimage, University of Illinois Press, Urbana, IL, 66-81.

Hunt, E. D. (1984): Holy Land Pilgrimage in the Later Roman Empire A.D.312-460, Clarendon Press, Oxford.

JAMES, L. (2001): Empresses and Power in Early Byzantium, Leicester University Press, London.

Keenan, G. J. (2000): “Egypt”, [en] A. Cameron - R. Ward-Perkins - M. Whitby (eds.), The Cambridge ancient history. Vol.14, Late antiquity: empire and successors, AD 425-600, Cambridge University Press, Cambridge, 612-637.

Kennedy, H. (2000): "Syria, Palestine and Mesopotamia”, [en] A. Cameron - R. Ward-Perkins - M. Whitby (eds.), The Cambridge ancient history. Vol.14, Late antiquity: empire and successors, AD 425-600, Cambridge University Press, Cambridge, 588-611.

Laiou, A. (1981): “The Role of Women in Byzantine Society”, JÖB 31/1, 233-260. 
MaAs, M. (2005): "Roman Questions, Byzantine Answers: Contours of the Age of Justinian", [en] M. Maas (ed.), The Cambridge companion to the Age of Justinian, Cambridge University Press, 3-27.

Maenchen-Helfen, O. J. (1957): “Germanic and Hunnic Names of Iranian Origin”, Oriens 10/2 (Dec. 31), 280-283.

Mango, C. (1959): The Brazen House: A Study of the Vestibule of the Imperial Palace of Constantinople, I Kommission Hos Ejnar Munksgaard, Copenhagen.

Marcos SÁnchez, Ma . M. (1996): "Representaciones visuales del poder en época tardoantigua: la imagen de la emperatriz”, Hispania Sacra 48, 513-540.

Millar, F. (1973): “The Imperial Cult and the Persecutions", [en] Le Culte des Souverains dans l'Empire Romain, Fondation Hardt, Genève, 143-165.

Mirón PÉrez, Ma . D. (1996): Mujeres, religión y poder: el culto imperial en el occidente mediterráneo, (=Colección Feminae 14), Universidad de Granada, Granada.

McCornick, M. (2000): "Emperor and Court", [en] A. Cameron - R. Ward-Perkins - M. Whitby (eds.), The Cambridge ancient history. Vol.14, Late antiquity: empire and successors, AD 425-600, Cambridge University Press, Cambridge, 135-163.

MoOrheAD, J. (1994): Justinian, Longman, London.

Ostrogorsky, G. (1980): History of the Byzantine State, Blackwell, Oxford.

Schubart, W. (1943): Justinian und Thedora, F. Bruckmann, München.

Signes Codoñer, J. (TRAD.), (2000): Historia Secreta. Procopio de Cesarea, Biblioteca Clásica Gredos, Madrid.

STERn, H. (1954): "Remarks on the adoratio under Diocletian", Journal of the Warburg and Courtauld Institutes 17/1-2, 184-189.

Treitinger, O. (1956): Die oströmische Kaiser- und Reichsidee nach ihrer Gestaltung im höfischen Zeremoniell: Vom oströmischen Staats- und Reichsgedanken, Wissenschaftliche Buchgesellschaft, Darmstadt.

Vilarrubias, O. (2005): Protocolo, Ceremonial, Heráldica y Vexilología en el Estado, en las corporaciones públicas y en la empresa multinacional, Universidad de Oviedo, Oviedo.

Zingale, L. M. (1984-85): “Osservazioni sulla domus divine di Teodora”, Annali Della Facoltà di Giurisprudenza di Genova 20, 142-149. 